\title{
COMMENTARY
}

\section{Critical care in the developing world - a challenge for us all}

\author{
Charles D Gomersall* \\ See related review by Du et al., http://ccforum.com/14/1/206
}

\begin{abstract}
The rapid economic growth in parts of the developing world is being accompanied by an expansion of critical care. Hurdles to expansion include lack of critical care training for healthcare workers. This is coupled with a need for a huge number of healthcare workers due to the high populations of countries such as China and India. Intensivists in the developed world can and should help.
\end{abstract}

The paper in the previous issue by $\mathrm{Du}$ and colleagues [1] describing critical care in China illustrates the increasing recognition and provision of critical care that follows economic development. Given that the two countries with the most rapid economic development, China and India, are also the two most populous countries in the world, this translates into a huge potential demand for critical care.

There are, however, a number of hurdles that need to be overcome in order to develop high quality intensive care, and the sheer size of the problem is mind-boggling: there are close to 2.9 million hospital beds in China. Current nursing provision in China is low, with a nurse:bed ratio of 1.37-2.02:1. This compares unfavourably with Western Europe, where 65\% of ICUs surveyed in 1996 reported higher ratios [2]. Moreover, critical care training of both nurses and doctors is limited. The authors highlight the fact that, while knowledge of state of the art advances is relatively easily acquired from conferences, basic knowledge and skills are inadequately taught.

Are these problems just for our colleagues in the developing world to deal with? The answer surely must be 'no. Patients are patients whatever their nationality and, as such, we have a responsibility to help improve

*Correspondence: gomersall@cuhk.edu.hk

Department of Anaesthesia and Intensive Care, The Chinese University of Hong Kong, Prince of Wales Hospital, Shatin, Hong Kong care beyond the confines of our own ICUs. So, how can we help? First we have to understand the problem by seeking more data on critical care outside developed countries. Papers such as that by Du and colleagues are a useful starting point and should be encouraged by journal editors. A worldwide registry of ICUs could provide even more useful and detailed data and a collaborative project to develop such a registry is currently underway [3]. Second, we can make educational material more widely available. This requires a change in attitude to intellectual property and sharing of resources. Why teach a handful of trainees in your unit when you could teach hundreds across the world? Why do we hand over copyright of book chapters to publishers with commercial interests when we could reach far more people by posting the chapters on the internet? Open access journals are a step in the right direction but, for developing countries, the emphasis may be in the wrong place. Research articles in Critical Care, for example, are free but review articles, which are probably of greater use to those requiring basic training, attract a fee. Third, we can try to make our teaching in developing countries more context specific. For example, there is little point in teaching about the latest ventilation modes if a basic understanding of ventilation is lacking.

However, all our efforts will be in vain if those who we train do not stay in their own countries. Migration, while addressing the systematic shortfall of staff in developed countries, is one of the underlying causes for the shortfall of healthcare workers in developing countries. The United States, for example, currently trains $30 \%$ too few doctors to meet its own needs and $\geq 25 \%$ of doctors in Canada, New Zealand, USA and UK were trained abroad [4]. We should tell our politicians that this is not acceptable.

Finally, $\mathrm{Du}$ and colleagues article illustrates the huge inequality that exists in many developing countries. In China the government covers only about $20 \%$ of healthcare costs. As the daily hospital cost for a patient with severe sepsis is US\$502 and the mean annual income in rural areas is only US\$697, it is obvious that critical care is out of the reach of the majority. This does not mean 
that we cannot help. As acute care specialists we can contribute to education in acute care as well as intensive care. Initiatives such as the Global Healthcare Workforce Alliance [5] are currently working to minimize the deficiency of 4.3 million healthcare workers in developing countries. With a high proportion of deaths in these countries resulting from acute illness or injury, acute care surely should have a place in the curriculum.

\section{Competing interests}

The author declares that he has no competing interests.

Published: 11 March 2010

\section{References}

1. Du B, Xi X, Chen D, Peng J; on behalf of China Critical Care Clinical Trial Group (CCCCTG): Clinical review: Critical care medicine in china mainland. Crit Care 2010, 14:206.

2. Depasse B, Pauwels D, Somers Y, Vincent JL: A profile of European ICU nursing. Intensive Care Med 1998, 24:939-945.

3. InFACT [http://www.infactglobal.org/]

4. Global Health Workforce Alliance [http://www.who.int/workforcealliance/en/]

5. World Health Organization: The Global Shortage of Health Workers and its Impact [http://www.who.int/mediacentre/factsheets/fs302/en/index.html]

doi:10.1186/cc8871

Cite this article as: Gomersall CD: Critical care in the developing world -

a challenge for us all. Critical Care 2010, 14:131. 